\title{
A EVOLUÇÃO DO MOVIMENTO DA TRIPLE HELIX: UMA ANÁLISE DAS COMUNICAÇÕES CIENTÍFICAS POR MEIO DE TÉCNICA BIBLIOMÉTRICA
}

\author{
THE EVOLUTION OF TRIPLE HELIX MOVEMENT: AN ANALYSIS OF SCIENTIFIC \\ COMMUNICATIONS THROUGH BIBLIOMETRIC TECHNIQUE \\ LA EVOLUCIÓN DEL MOVIMIENTO DE TRIPLE HÉLICE: UN ANÁLISIS DE LAS \\ COMUNICACIONES CIENTÍFICAS MEDIANTE TÉCNICA BIBLIOMÉTRICA
}

\section{Marcelo Gonçalves do Amaral ${ }^{1}$}

Nathan Ribeiro Messias ${ }^{2}$

Cite as - American Psychological Association (APA)

Amaral, M. G., \& Messias, N. R. (2020, May/Aug.). A evolução do movimento da triple helix: uma análise das comunicações científicas por meio de técnica bibliométrica. International Journal of Innovation - IJI, São Paulo, 8(2), 250-275. https://doi.org/10.5585/iji.v8i2.17396.

\section{Resumo}

Objetivo: O objeto deste trabalho teórico-empírico é analisar a evolução do movimento da Triple Helix com base na análise do banco de publicações científicas por meio de técnicas bibliométricas.

Metodologia: Trata-se de uma pesquisa exploratória aplicada. O banco de publicações está estruturado como um arquivo MS Excel alimentado manualmente a partir dos anais das conferências internacionais e outras publicações. Periodicamente o banco é congelado e são contabilizados os principais autores, instituições, países de origem e temas.

Originalidade: $\mathrm{O}$ trabalho é original na ideia de conhecer um movimento acadêmico por meio dos seus resultados.

Principais resultados: $\mathrm{O}$ banco reúne 2.700 entradas (24\% de artigos de periódicos, $70 \%$ de comunicações de conferências e $6 \%$ de livros, capítulos e outros). As comunicações foram escritas por 3.465 autores, uma média de 1,28 autores por trabalho. Como esperado, os criadores do conceito, Henry Etzkowitz e Loet Leydesdorff, juntos ou com parceiros, são responsáveis por $9,4 \%$ de todas as comunicações. Países como Brasil, Reino Unido, EUA, Rússia e Itália demonstram maior atividade no movimento, e organizar uma conferência foi crucial para a disseminação do conceito em seus países.

Contribuições teóricas: $O$ trabalho contribui para que se compreenda melhor o campo de atuação da temática da Triple Helix. É útil para pesquisadores procurando literatura, lacunas e temas de pesquisa.

Contribuições para a gestão: O trabalho apresenta contribuições para Triple Helix Association na gestão do movimento e para os organizadores das conferências, em geral universidades, e seus parceiros.

\footnotetext{
${ }^{1}$ Universidade Federal Fluminense - UFF, Volta Redonda, RJ - Brasil. marceloamaral@id.uff.br

${ }^{2}$ Universidade Federal Fluminense - UFF, Volta Redonda, RJ - Brasil. nathan_messias@ @otmail.com
} 
Palavras-chave: Triple Helix. Banco de publicações. Comunicações científicas.

\begin{abstract}
Objective: The object of this theoretical-empirical work is to analyze the evolution of the Triple Helix movement based on the analysis of the scientific publications database through bibliometric techniques.

Methodology: This is an applied exploratory research. The publications database is structured as an MS Excel file fed manually from the annals of international conferences and other publications. The database is periodically frozen and the main authors, institutions, countries of origin, and topics are counted.
\end{abstract}

Originality: The work is original in the idea of knowing an academic movement through its results.

Main results: The database gathers 2,700 inputs (24\% journal papers, $70 \%$ conferences communications, and $6 \%$ books, chapters, and others). These communications were written by 3,465 authors, an average of 1.28 authors per work. As expected, the creators of the concept, Henry Etzkowitz and Loet Leydesdorff, together or with partners, are responsible for $9.4 \%$ of all communications. Countries such as Brazil, the UK, the USA, Russia, and Italy are very active in the movement and organizing a conference was crucial to the dissemination of the concept in their countries.

Theoretical contributions: The work contributes to a better understanding of the field of action of the Triple Helix theme. It is useful for researchers looking for literature, gaps, and research topics.

Management contributions: The work presents contributions to the Triple Helix Association in the management of the movement and to conference organizers, in general universities, and their partners.

Keywords: Triple Helix. Publications database. Scientific communications.

\title{
Resumen
}

Objetivo: El objeto de este trabajo teórico-empírico es analizar la evolución del movimiento de la Triple Hélice a partir del análisis de la base de datos de publicaciones científicas mediante técnicas bibliométricas.

Metodología: Es una investigación exploratoria aplicada. La base de datos de publicaciones está estructurada como un archivo MS Excel alimentado manualmente de conferencias internacionales y otras publicaciones. El banco se congela periódicamente y se contabilizan los principales autores, instituciones, países de origen y temáticas.

Originalidad: El trabajo es original en la idea de conocer un movimiento académico a través de sus resultados.

Resultados principales: La base de datos reúne 2.700 entradas (24\% artículos de revistas, $70 \%$ comunicaciones de conferencias y $6 \%$ libros, capítulos y otros). Las comunicaciones fueron escritas por 3.465 autores, una media de 1,28 autores por comunicación. Como era de esperar, los creadores del concepto, Henry Etzkowitz y Loet Leydesdorff, junto o con compañeros, son responsables del 9,4\% de todas las comunicaciones. Países como Brasil, Reino Unido, Estados Unidos, Rusia e Italia son muy activos en el movimiento y organizar una conferencia fue crucial para la difusión del concepto en sus países.

Aportes teóricos/metodológicos: El trabajo contribuye a una mejor comprensión del campo de acción del tema Triple Hélice. Es útil para investigadores que buscan literatura, lagunas y temas de investigación. 
Contribuciones sociales / de gestión: El trabajo presenta contribuciones a la Asociación Triple Hélice en la gestión del movimiento y a los organizadores de conferencias, en general las universidades, y sus socios.

Palabras clave: Triple Hélice. Banco de publicaciones. Comunicaciones científicas.

\section{Introdução}

A abordagem da Triple Helix (TH), Hélice Tríplice ou Hélice Tripla em português, é uma metáfora para a compreensão e análise dos sistemas de inovação, proposta em 1994 por Henry Etzkowitz e Loet Leydesdorff. Os autores difundiram a TH ao longo dos últimos 24 anos como um modelo que interpreta de forma mais completa a interação entre atores das esferas que geram conhecimento (universidade ou academia), que utilizam conhecimento (setor produtor de bens e serviços) e o setor que regula e fomenta a atividade econômica (governo), com fins de promover a inovação e o desenvolvimento econômico e social (ETZKOWITZ, 2008). Diferentemente da abordagem do sistema nacional de inovação que foca na existência dos atores supondo que as relações entre eles seria um processo natural, a TH enfatiza a interação e a dinâmica trilateral entre atores e esferas (AMARAL et al., 2020). A abordagem, apesar de incompleta, pode ser utilizada como uma ferramenta analítica ex-post e como uma inspiração para a proposição de políticas públicas de ciência, tecnologia e inovação (AMARAL et al., 2011). Seu estudo é relevante para compreender e apoiar o desenvolvimento tecnológico, econômico e social no século XXI e tem contribuições práticas (AMARAL et al., 2020).

Em termos acadêmicos a TH emergiu como um modelo e vem sendo amplamente estudada em áreas como economia, gestão e sociologia. Como movimento acadêmico, as conferências (iniciadas em 1996 e atualmente na XVIII edição) e as publicações levaram a criação da Triple Helix Association (THA), em 2009, e do Triple Helix Journal, em 2014, além de diversos capítulos nacionais (Brasil, Rússia, Grécia, Cazaquistão, South Asia - SATHA, e Alemanha). Diversos outros produtos, como cursos de curta duração, webinars, jogos (Trilicious) e um banco de publicações científicas foram criados pelos pesquisadores e praticantes do movimento.

O banco de comunicações científicas sobre a TH começou a ser desenvolvido em 2009 como parte das iniciativas relacionadas à organização da VIII Conferência Internacional da TH, realizada em outubro de 2010 em Madri, Espanha. A equipe organizadora da conferência identificou a necessidade de inteirar-se sobre a produção acadêmica dos eventos anteriores, visando definir os temas mais relevantes para a chamada de trabalhos (Call for papers). A ideia era de conhecer os temas tradicionais ou comuns, presentas na maior parte das conferências 
anteriores, e nos quais os autores envolvidos com a temática teriam facilidade em submeter manuscritos, e combiná-los com novos temas, de interesse dos organizadores da VIII conferência e seus stakeholders (financiadores, governos locais, entre outros). Adicionalmente, a base de publicações serve como uma ferramenta de inteligência de negócios (business intelligence) para identificar os principais autores e instituições pesquisando sobre a $\mathrm{TH}$, visando convidá-los para participar (e liderar atividades) na conferência e, também, descobrir quais instituições com atividade na temática que não estavam participando nos eventos e envolve-las (AMARAL e FERREIRA, 2013).

O banco de comunicações contribuiu para a realização de uma conferência bemsucedida no ano de 2010 (com 116 trabalhos apresentados). A partir de 2011 se tornou um projeto/produto do Triple Helix Research Group (THERG-Brazil), grupo de pesquisas criado em 2008, atualmente sediado no Programa de Pós-Graduação em Administração da Universidade Federal Fluminense (UFF). Ao longo dos anos atualizações têm sido disponibilizadas para estudiosos do tema, para a THA, e organizadores das conferências. As versões foram disponibilizadas em 2010, 2013, 2017 e 2018 (ROSA et al., 2018).

Pesquisando na literatura não é comum encontrar discussões relacionadas com a evolução de movimentos acadêmicos. É comum o uso de técnicas bibliométricas em revisões de literatura sobre um tema ou modelo/ferramenta perfazendo um panorama sobre aquele tema. Portanto, a lacuna de pesquisa é como melhorar o conhecimento e compreender a evolução de um movimento acadêmico como a TH ao longo dos anos. Com base nos produtos acadêmicos resultantes da atividade de pesquisa, a questão explorada neste artigo é Quem são os principais autores, instituições e países e quais são suas agendas de pesquisa? Uma discussão secundária do artigo é sobre o impacto de sediar uma conferência na permanência destes autores, instituições e países no movimento. Assume-se que ao organizar um evento a instituição e o país respectivo sigam envolvidos com o movimento.

O objeto deste trabalho teórico-empírico é analisar a evolução do movimento da TH com base na análise do banco de publicações científicas por meio de técnicas bibliométricas. É, portanto, um trabalho de pesquisa aplicada de cunho exploratório, sendo útil principalmente aos gestores de eventos científicos, na elaboração da chamada de trabalhos e organização de sessões científicas, e pesquisadores, que podem encontrar fontes para revisão bibliográfica e lacunas/problemáticas para pesquisa/discussão acadêmica.

Para atingir o objetivo proposto, o trabalho é estruturado em cinco partes contando com esta introdução. A segunda parte uma breve conceituação de técnicas bibliométricas. A terceira seção visa explicar os procedimentos metodológicos para a construção do banco de 
comunicações científicas. A quarta parte apresenta uma análise a partir das informações retiradas do banco, seguida da quinta parte com as considerações finais do trabalho.

\section{Sobre as técnicas bibliométricas}

A utilização de técnicas estatísticas para mensuração de documentos existe desde o século XIX. Originalmente conhecida como bibliografia estatística, o termo bibliometria foi cunhado pelo autor belga Paul Otlet no trabalho Traité de Documentation: le livre sur le livre: théorie et pratique, publicado em 1934. O autor, que é conhecido como um dos pais da ciência da documentação, tinha como objetivo encontrar meios de mensurar a crescente quantidade de material publicado, entre livros e documentos, através de estatística e modelos matemáticos, dando assim, um carácter científico à classificação dos trabalhos publicados (SANTOS, 2007; ALVARADO, 2007).

A bibliometria pode ser definida como um conjunto coordenado de regras para classificar a organização de livros e documentos, ou seja, uma área oriunda da ciência da informação com o objetivo de se fazer a análise da produção científica (OTLET, 1934). Silva, Hayashi \& Hayashi (2011, p. 113-114) ampliam a discussão ao argumentarem que “...é um método flexível para avaliar a tipologia, a quantidade e a qualidade das fontes de informação...”.

Para Mueller (2013, p.17) esta ciência visa a "análise e mapeamento de autorias e coautorias, colaboração e redes; avaliação e descrição da literatura, impacto e indicadores; produção e produtividade, visibilidade de autores e instituições; estudos de citação e cocitação". Sendo assim, é possível medir o surgimento de novos temas, identificar o crescimento do conhecimento em uma determinada área e suas possíveis tendências. É possível ainda, identificar a influência de autores, países e organizações (GIUSTI et al., 2011).

Salienta-se que a área da ciência da informação não compreende apenas a bibliometria. Ela engloba diversas outras áreas como a cienciometria, a informetria e a webometria. $\mathrm{Na}$ literatura acadêmica existe um debate sobre a conceituação e diferenças entre os termos. Autores como Sengputa (1992) e Gläzel \& Schoepflin (1994) afirmam que bibliometria, informetria e cientometria são sinônimos, enquanto autores como Egghe (1994) e TagueSutckiffe (1992) consideram que a infometria englobaria a bibliometria e, por isso, seria mais ampla do que a cientometria (VANTI, 2002). Fatores como o objeto de estudo, suas variáveis, métodos e objetivos são determinantes na diferenciação das áreas, como pode ser observado no Quadro 1. 
Quadro 1 - Comparação das aplicações dos distintos métodos quantitativos

\begin{tabular}{|c|c|c|c|c|}
\hline SOBRE & $\begin{array}{c}\text { BIBLIOME- } \\
\text { TRIA }\end{array}$ & CIENCIOMETRIA & INFORMETRIA & WEBOMETRIA \\
\hline $\begin{array}{l}\text { Objeto de } \\
\text { Estudo }\end{array}$ & $\begin{array}{l}\text { Livros, } \\
\text { documentos, } \\
\text { revistas, } \\
\text { artigos, } \\
\text { autores, } \\
\text { usuários. }\end{array}$ & $\begin{array}{l}\text { Disciplinas, assuntos, } \\
\text { áreas e campos } \\
\text { científicos e } \\
\text { tecnológicos. Patentes, } \\
\text { dissertações e teses. }\end{array}$ & $\begin{array}{l}\text { Palavras, documentos, } \\
\text { bases de dados, } \\
\text { comunicações informais } \\
\text { (inclusive em âmbitos não } \\
\text { científicos), home pages na } \\
\text { www. }\end{array}$ & $\begin{array}{l}\text { Sítios na www (URL, } \\
\text { título, tipo, domínio, } \\
\text { tamanho e links), } \\
\text { motores de busca. }\end{array}$ \\
\hline Variáveis & $\begin{array}{l}\text { Número de } \\
\text { empréstimos } \\
\text { (circulação) e } \\
\text { de citações, } \\
\text { frequência de } \\
\text { extensão de } \\
\text { frases. }\end{array}$ & $\begin{array}{l}\text { Fatores que } \\
\text { diferenciam as } \\
\text { subdisciplinas. Como } \\
\text { os cientistas se } \\
\text { comunicam. }\end{array}$ & $\begin{array}{l}\text { Difere da cienciometria no } \\
\text { propósito das variáveis, por } \\
\text { exemplo, medir a } \\
\text { recuperação, a relevância, } \\
\text { a revocação. }\end{array}$ & $\begin{array}{l}\text { Número de páginas } \\
\text { por sítio, } \mathrm{n}^{\circ} \text { de links } \\
\text { por sítio, } \mathrm{n}^{\circ} \text { de links } \\
\text { que remetem a um } \\
\text { mesmo sítio, } \mathrm{n}^{\circ} \text { de } \\
\text { sítios recuperados. }\end{array}$ \\
\hline Métodos & $\begin{array}{l}\text { Ranking, } \\
\text { frequência, } \\
\text { distribuição. }\end{array}$ & $\begin{array}{l}\text { Análise de conjunto e } \\
\text { de correspondência, } \\
\text { coocorrência de } \\
\text { termos, expressões, } \\
\text { palavras-chave etc. }\end{array}$ & $\begin{array}{l}\text { Modelo vetor-espaço, } \\
\text { modelos booleanos de } \\
\text { recuperação, modelos } \\
\text { probabilísticos; linguagem } \\
\text { de processamento, } \\
\text { abordagens baseadas no } \\
\text { conhecimento, tesauros. }\end{array}$ & $\begin{array}{l}\text { Fator de impacto da } \\
\text { web (FIW), } \\
\text { densidade dos links, } \\
\text { "situações", } \\
\text { estratégias de busca. }\end{array}$ \\
\hline Objetivos & $\begin{array}{l}\text { Alocar } \\
\text { recursos: } \\
\text { pessoas, } \\
\text { tempo, } \\
\text { dinheiro etc. }\end{array}$ & $\begin{array}{l}\text { Identificar domínios } \\
\text { de interesse. Onde os } \\
\text { assuntos são } \\
\text { concentrados. } \\
\text { Compreender como e } \\
\text { quanto os cientistas se } \\
\text { comunicam. }\end{array}$ & $\begin{array}{l}\text { Melhorar a eficiência da } \\
\text { recuperação da } \\
\text { informação, identificar } \\
\text { estruturas e relações dentro } \\
\text { dos diversos sistemas de } \\
\text { informação. }\end{array}$ & $\begin{array}{l}\text { Avaliar o sucesso de } \\
\text { determinados sítios, } \\
\text { detectar a presença } \\
\text { de países, instituições } \\
\text { e pesquisadores na } \\
\text { rede e melhorar a } \\
\text { eficiência dos } \\
\text { motores de busca. }\end{array}$ \\
\hline
\end{tabular}

Fonte: Elaborado pelos autores com base em Vanti (2002, p. 160).

\section{Métodos e materiais}

O estudo realizado neste artigo pode ser classificado como bibliométrico, pois os métodos a serem utilizados se baseiam em medições de frequências e organização de rankings. Entretanto, também engloba aspectos de cienciometria, por lidar com um ramo específico do conhecimento: as relações universidade-empresa-governo dentro da subárea de gestão da inovação, que faz parte da área de estratégia no campo da Administração; e tentar organizá-la. Existem ainda aspectos de informetria, pois vai além da documentação científica tradicional (artigos) e aceita na base de dados outras comunicações como artigos de anais de congressos, trabalhos apresentados em congressos, palestras, webinars e artigos de exposição de ideias (working papers). Por fim, aspectos de webometria também surgem pela disseminação de bases na internet e documentação disponíveis em websites.

Quanto aos procedimentos metodológicos, o trabalho desenvolveu uma pesquisa documental para revisão da literatura sobre bibliometria, selecionando técnicas que serão utilizadas no banco; acesso ao banco disponível no blog do THERG-Brazil 
(http://triplehelixbrasil.blogspot.com) e aplicação das técnicas selecionadas; e análise dos dados e redação. A revisão de literatura foi realizada no ano de 2018 e a análise e redação entre o segundo semestre de 2019 e o primeiro de 2020.

Sua contribuição é, a partir da análise de distribuição das publicações, ampliar o conhecimento acerca do envolvimento de atores de diferentes países ao longo do tempo com a temática. Além disso, entende-se que tal tipo de esforço permite uma melhor compreensão do movimento científico pela própria comunidade participante.

\subsection{Procedimentos para a Construção do Banco de Comunicações}

O banco de comunicações, inicialmente, foi financiado pela Fundación La Salle Parque de Innovación, da Espanha, que sediava o International Institute of Triple Helix, entidade organizadora da conferência no ano de 2010. Desde 2011, o trabalho foi assumido pelo grupo de pesquisas sobre a TH sediado na UFF. Suas atividades vêm sendo financiadas com recursos da própria universidade, em parceria com o CNPQ, via programas institucionais de incentivo à iniciação científica e tecnológica, e como atividade de projetos de pesquisa financiados pela Fundação Carlos Chagas Filho de Apoio à Pesquisa no Estado do Rio de Janeiro (FAPERJ). O banco pode ser entendido, no âmbito da mensuração da atividade acadêmica, como um produto tecnológico (AMARAL e FERREIRA, 2013).

Para lidar com a variedade de materiais disponíveis optou-se por utilizar o constructo "comunicação científica", em lugar de "publicação" ou "artigo", como o elemento chave de "entrada" no banco. Este termo visa diferenciar o que é científico do que não é, excluindo comunicações não acadêmicas (artigos de opinião ou publicados em jornais; ensaios que não tenham caráter e estrutura de uma produção científica). Permite, adicionalmente, ampliar o escopo de pesquisa, abrangendo não somente os artigos publicados em periódicos indexados, mas também as publicações relacionadas à conferências acadêmicas, que deram a motivação original para o projeto. Utiliza-se ainda o termo "entrada" como sinônimo de "comunicação" (ROSA et al., 2018).

O lançamento das comunicações segue alguns critérios. O primeiro, e principal, é a participação dos autores nas conferências da TH. Além das quinze conferências internacionais, outros eventos regionais foram lançados, conforme apresentados no Quadro 2. Em segundo, observa-se se publicações de números especiais de periódicos acadêmicos a partir das conferências, nas quais destacam-se de títulos como Scientometrics, Industry and Higher Education, Science and Public Policy, dentre outros. Mais recentemente, o site da Triple Helix Association (THA) passou a ser uma fonte relevante de informações, pois vem trabalhando na 
construção de um repositório de publicações, além de organizar webinars e disseminar working papers. Para a versão de 2018 foi feito um levantamento junto às bases de dados Web of Science e Scielo, confirmando a presença de publicações em periódicos indexados, e ampliando a base de autores. As conferências mais recentes (2018 e 2019) ainda estão sendo lançadas no banco. Os anais da conferência de 2020, realizada no último mês de Junho, ainda não está disponível. Foi feita ainda uma opção em manter o cadastro em inglês visto que a maior parte das comunicações é feita neste idioma.

Quadro 2 - Conferências da Triple Helix

\begin{tabular}{|c|c|c|c|c|c|c|}
\hline Ano & $\begin{array}{c}\text { Internac. } \\
\text { ou regional }\end{array}$ & Cidade/País & $\begin{array}{c}\text { Entidade } \\
\text { organizadora }\end{array}$ & $\begin{array}{c}\text { Coordenador } \\
\text { geral }\end{array}$ & Mês & $\begin{array}{l}\text { Presentes/ } \\
\text { Trabalhos } \\
\end{array}$ \\
\hline 1996 & Internac. & Amsterdã/HOL & $\begin{array}{l}\text { University of } \\
\text { Amsterdã }\end{array}$ & Loet Leydesdorff & Jan & n.d. \\
\hline 1998 & Regional & $\begin{array}{l}\text { Nova } \\
\text { Iorque/EUA }\end{array}$ & $\begin{array}{l}\text { State University of } \\
\text { New York }\end{array}$ & Henry Etzkowitz & Jan & $136 / 106$ \\
\hline 1999 & Regional & $\begin{array}{l}\text { Rio de } \\
\text { Janeiro/BRA }\end{array}$ & $\begin{array}{l}\text { Universidade Federal } \\
\text { do Rio de Janeiro }\end{array}$ & $\begin{array}{l}\text { José Manoel } \\
\text { Carvalho de Mello }\end{array}$ & Jun & n.d./19 \\
\hline 2000 & Internac. & $\begin{array}{l}\text { Rio de } \\
\text { Janeiro/BRA }\end{array}$ & $\begin{array}{l}\text { Universidade Federal } \\
\text { do Rio de Janeiro }\end{array}$ & $\begin{array}{l}\text { José Manoel } \\
\text { Carvalho de Mello }\end{array}$ & Abr & $400 / 130$ \\
\hline 2002 & Internac. & $\begin{array}{l}\text { Copenhague/ } \\
\text { DIN; Lund/SUE }\end{array}$ & $\begin{array}{l}\text { Copenhague Business } \\
\text { School }\end{array}$ & Merle Jacob & Nov & $127 / 99$ \\
\hline 2005 & Internac. & Turim/ITA & Fondazione Rosseli & Riccardo Viale & Mai & $163 / 136$ \\
\hline 2006 & Regional & $\begin{array}{l}\text { Addis Abbeba / } \\
\text { ETI }\end{array}$ & n.d & n.d. & Mai & $19 / 24$ \\
\hline 2007 & Internac. & Cingapura & $\begin{array}{l}\text { National University of } \\
\text { Singapore }\end{array}$ & Pom Kah Wong & Mai & $220 / 137$ \\
\hline 2009 & Internac. & Glasgow/ESC & $\begin{array}{l}\text { University of } \\
\text { Strathclyde }\end{array}$ & Tariq Durrani & Jun & $300 / 189$ \\
\hline 2009 & Regional & $\begin{array}{l}\text { Porto } \\
\text { Alegre/BRA }\end{array}$ & PUC-RS & $\begin{array}{l}\text { Marli Elizabeth } \\
\text { Ritter dos Santos }\end{array}$ & Nov & $24 / 30$ \\
\hline 2010 & Internac. & Madrid/ESP & $\begin{array}{l}\text { Centro Superior de } \\
\text { Estudios } \\
\text { Universitarios La } \\
\text { Salle }\end{array}$ & $\begin{array}{l}\text { Marcelo Amaral \& } \\
\text { Raphael Zaballa }\end{array}$ & Out & $181 / 116$ \\
\hline 2011 & Internac. & Palo Alto/ EUA & Stanford University & Henry Etzkowitz & Jul & $164 / 110$ \\
\hline 2012 & Internac. & Bandung/ IND & $\begin{array}{l}\text { Institut Teknologi } \\
\text { Bandung (ITB) }\end{array}$ & $\begin{array}{l}\text { Tariq Durrani \& } \\
\text { Dr. Akhmaloka }\end{array}$ & Ago & $218 / 121$ \\
\hline 2013 & Internac. & Londres/ING & $\begin{array}{l}\text { Birkbeck, University } \\
\text { College London }\end{array}$ & Birgitte Andersen & Jul & $202 / 189$ \\
\hline 2014 & Internac. & Tomsk/RUS & $\begin{array}{l}\text { Tomsk State } \\
\text { Univesrity }\end{array}$ & Alexander Uvarov & Set & $209 / 126$ \\
\hline 2015 & Internac. & Beijing / CHI & Tsinghua University & Chen Jin & Ago & $65 / 40$ \\
\hline 2016 & Internac. & Heidelberg/ALE & $\begin{array}{l}\text { German Cancer } \\
\text { Research Center }\end{array}$ & Djordje Pinter & Set & $43 / 42$ \\
\hline 2017 & Regional & Nairobi / QUE & I Choose Life-Africa & Mike Mutungi & Abr & $1153 / 47$ \\
\hline 2017 & Internac. & Daegu/COR & Asialics Korea & Dong Joo Song & Set & $34 / 27$ \\
\hline
\end{tabular}

Fonte: Elaborado pelos autores.

Legenda: n.d. - não disponível.

O banco permite o uso de técnicas bibliométricas para analisar a produção científica sobre o tema TH. Sua vantagem em relação ao uso de base de dados mundialmente consolidadas 
como Scopus, Scielo ou Web of Science é que envolve um trabalho minucioso de cadastramento e o foco não está limitado aos periódicos indexados, mas inclui também publicações em conferências, seminários e eventos, além de palestras. Material que é relevante mas não encontrado nas bases consolidadas. Entende-se que a menor parte das comunicações feitas em congressos atingem o nível de serem publicadas em periódicos acadêmicos indexados nas bases internacionais. A maior parte integram dissertações e teses ou limitam-se a serem publicadas apenas nos próprios congressos científicos.

Quanto à estrutura, o banco de comunicações foi estruturado no MS Excel contendo doze metadados, conforme apresentado no Quadro 3. O fato de estar em MS Excel facilita o uso por pesquisadores menos experientes e permite simultaneamente a migração para softwares especializados no tratamento de dados. O fato do banco estar disponível no blog do grupo de pesquisas também amplia o acesso e a qualidade dos dados, pois autores podem enviar trabalhos para serem incluídos e/ou corrigir informações das comunicações já incluídas.

Quadro 3 - Metadados constituintes do banco de comunicações

\begin{tabular}{|c|c|}
\hline Metadados & Descrição/Categorias \\
\hline Entrada & Número de referência do artigo \\
\hline Ano (Year) & Ano de publicação \\
\hline $\begin{array}{l}\text { Tipo de publicação } \\
\text { (Type of publication) }\end{array}$ & $\begin{array}{l}\text { Livro/capítulo de livro; Conferência (identificado qual TH ou apenas conferência } \\
\text { se outra); Periódico (com especial identificação se for o Triple Helix Journal); } \\
\text { Monografia/Dissertação/Tese; texto de discussão/working paper; } \\
\text { apresentação/palestra/keynote em evento científico. No caso de conferências da TH, } \\
\text { todos os eventos a partir da segunda edição estão incluídos (não foram feitos anais } \\
\text { da primeira reunião) e vários eventos regionais também foram incluídos. }\end{array}$ \\
\hline $\begin{array}{l}\text { Sessão/Temas } \\
\text { (Session/themes) }\end{array}$ & $\begin{array}{l}\text { No caso das conferências há um conjunto de temas principais na chamada de artigos } \\
\text { que se refletem nas sessões da programação. }\end{array}$ \\
\hline Autor(es) (Authors) & $\begin{array}{l}\text { Nome completo do autor, sendo que cada autor equivale a uma linha no banco de } \\
\text { artigos (isto é, se um artigo tem } 4 \text { autores, serão } 4 \text { linhas no banco) }\end{array}$ \\
\hline Instituição (Institution) & Instituição de filiação do autor no momento da publicação \\
\hline País (Country) & $\begin{array}{l}\text { País de origem ou sede da instituição (pode ser universidade, centro de pesquisa, } \\
\text { órgão governamental, empresa ou similares). Artigos com vários autores de } \\
\text { diferentes países são contabilizados pelo país do primeiro autor. }\end{array}$ \\
\hline $\begin{array}{l}\text { Palavras-chave } \\
\text { (Keyword) }\end{array}$ & $\begin{array}{l}\text { Palavras que identificam a área da publicação, muito comum em artigos de } \\
\text { congressos e publicados em periódicos, serve também para classificar livros; o } \\
\text { campo não tem limite de tamanho e as palavras são separadas por vírgula. }\end{array}$ \\
\hline Fontes (Sources) & $\begin{array}{l}\text { Informa a fonte da publicação (se um periódico diz o nome do periódico, volume, } \\
\text { número e páginas) ou então o link de onde a publicação pode ser encontrada. }\end{array}$ \\
\hline Título (Title) & Título da publicação. \\
\hline $\begin{array}{l}\text { Base de dados } \\
\text { (Database) }\end{array}$ & $\begin{array}{l}\text { Informa em qual base de dados foi encontrada a publicação (caso ela for indexada). } \\
\text { Ex: Scopus, Web of Science. }\end{array}$ \\
\hline DOI & $\begin{array}{l}\text { Identificação para publicações indexadas visando o fácil acesso à mesma (é possível } \\
\text { apresentar o link da página do periódico ou local de publicação). }\end{array}$ \\
\hline
\end{tabular}

Fonte: Elaborado pelos autores. 


\section{0 banco de comunicações}

Esta análise está dividida em duas partes. A primeira apresenta indicadores gerais sobre o banco de comunicações como autores, países, instituições e temas mais relevantes. A segunda trata especificamente da participação de cada país que sediou alguma conferência.

\subsection{Indicadores Gerais}

O banco de artigos conta na versão 2018 com exatas 2.700 entradas, sendo 1.950 trabalhos publicados em congressos (72\%), 643 artigos publicados em periódicos (23,8\%), 44 livros e capítulos de livros (1,6\%), 27 monografias, dissertações e teses (1\%) e 36 outros tipos de comunicações. Estas 2.700 publicações foram realizadas por 3.465 autores, uma média de 1,28 autores por comunicação. Analisando desde o início dos anos noventa, quando a TH foi proposta, é possível ver que o tema vem repercutindo. A Figura 1 mostra o quantitativo de comunicações anuais, constatando um crescimento nos anos de conferência (1998, 2000, 2002, 2005 e 2007) e um crescimento significativo a partir de 2009, quando sua periodicidade passou a ser anual. Entre 2009 e 2014 foram realizadas 1.319 das 2.700 comunicações $(48,85 \%)$. Nos últimos anos o volume de comunicações caiu, possivelmente por conta da realização das conferências em países orientais (China e Coréia do Sul) longe do eixo Estados Unidos-Europa, e, adicionalmente, porque as últimas comunicações ainda não foram inseridas na base.

Figura 1 - Volume de entradas por ano no banco de comunicações

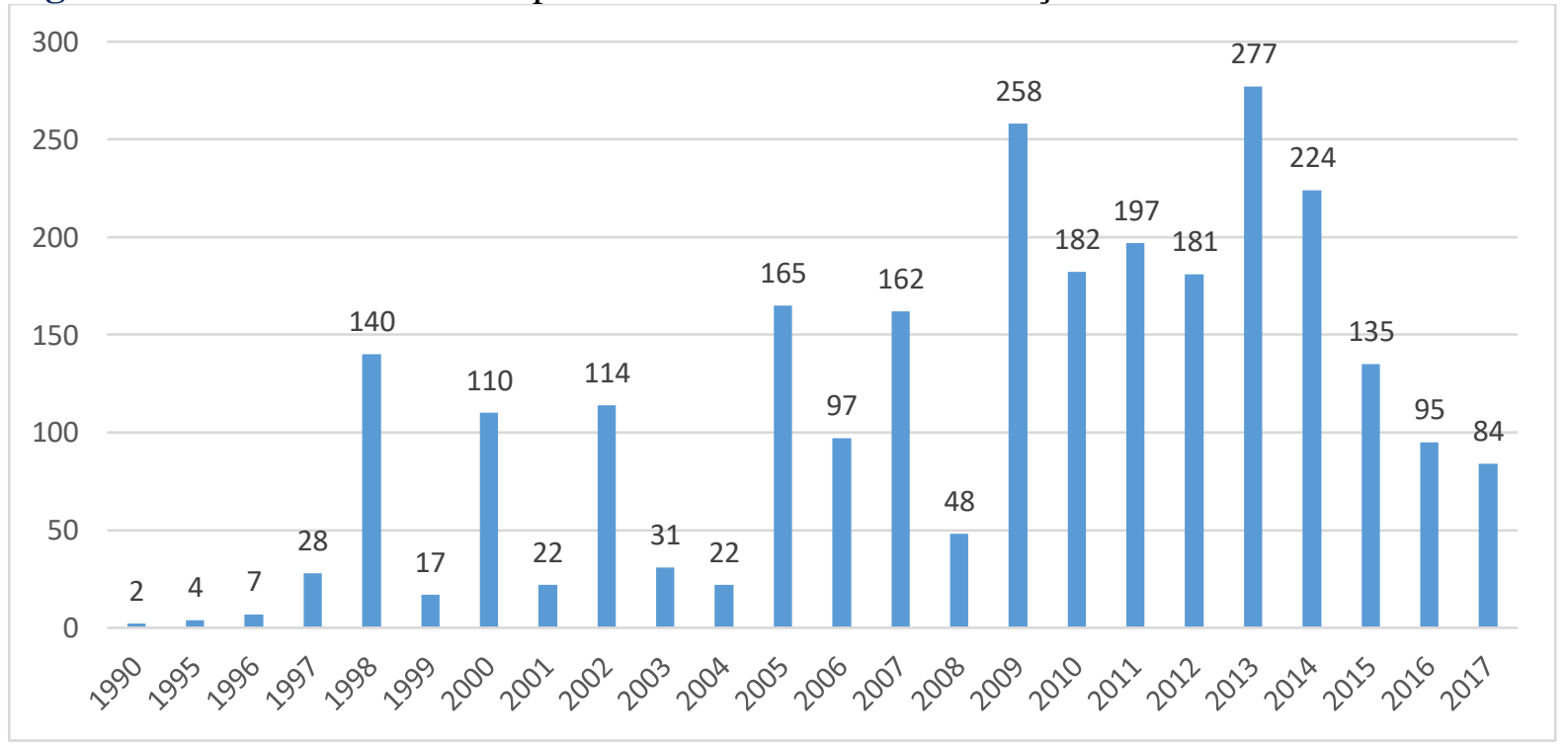

Fonte: Elaborado pelos autores. 
Os principais autores sobre o tema são os próprios criadores da abordagem, os professores Henry Etzkowitz e Loet Leydesdorff, com 255 publicações ao todo, seja elas em conjunto, ou com inúmeros e diferentes parceiros, totalizando 9,4\% do volume de trabalhos. Seguidos por Martin Meyer (Reino Unido), Han Woo Park (Coréia do Sul), José Manoel Carvalho de Mello (Brasil), Branca Terra (Brasil), Mariza Almeida (Brasil) e outros, que totalizam 566 comunicações, ou 21\% do total do banco, vide Quadro 4.

Quadro 4 - Vinte autores com maior número de comunicações

\begin{tabular}{|c|c|}
\hline Autores & Quantidade e tipo de publicação \\
\hline Loet Leydesdorff & $\begin{array}{l}156 \text { entradas ( } 4 \text { livros, } 5 \text { capítulos de livros, } 23 \text { conferências, } 119 \text { periódicos, } 1 \\
\text { relatório, } 4 \text { não identificados }{ }^{1} \text { ) }\end{array}$ \\
\hline Henry Etzkowitz & $\begin{array}{l}99 \text { entradas ( } 5 \text { livros, } 3 \text { capítulos de livros, } 20 \text { conferências, } 68 \text { periódicos, } 2 \\
\text { working papers, } 1 \text { não identificado }{ }^{1} \text { ) }\end{array}$ \\
\hline Martin Meyer & 30 entradas ( 15 conferências, 15 periódicos $)$ \\
\hline Han Woo Park & 29 entradas ( 8 conferências, 21 periódicos $)$ \\
\hline José Manoel Mello & 22 entradas ( 1 capítulo de livro, 16 conferências, 5 periódicos) \\
\hline Branca Terra & 21 entradas ( 1 capítulo de livro, 13 conferências, 7 periódicos) \\
\hline Mariza Almeida & 20 entradas ( 1 capítulo de livro, 14 conferências, 5 periódicos) \\
\hline Girma Zawdie & 19 entradas ( 2 capítulos de livros, 10 conferências, 7 periódicos) \\
\hline Bart Van Looy & 17 entradas ( 11 conferências, 6 periódicos) \\
\hline Mohammed Saad & 17 entradas (4 capítulos de livro, 7 conferências, 6 periódicos) \\
\hline Réjean Landry & 16 entradas ( 11 conferências, 6 periódicos) \\
\hline Chunyan Zhou & 15 entradas (6 conferências, 9 periódicos $)$ \\
\hline Marcelo Amaral & 15 entradas ( 12 conferências, 3 periódicos) \\
\hline Denis O. Gray & 14 entradas ( 11 conferências, 3 periódicos) \\
\hline Elias G. Carayannis & 14 entradas (4 conferências, 10 periódicos) \\
\hline Christiane Gebhardt & 13 entradas ( 9 conferências, 4 periódicos) \\
\hline Poh Kam Wong & 13 entradas (9 conferências, 4 periódicos) \\
\hline Alexander Uvarov & 12 entradas ( 11 conferências, 1 periódico) \\
\hline Magnus Gulbrandsen & 12 entradas ( 1 capítulo de livro, 8 conferências, 3 periódicos) \\
\hline Nabil Amara & 12 entradas ( 10 conferências, 2 periódicos $)$ \\
\hline
\end{tabular}

Fonte: Elaborado pelos autores.

${ }^{1}$ Versões preliminares (draft) de comunicações científicas

É interessante notar que dentre estes vinte autores, seis foram os organizadores das conferências internacionais (Loet Leydesdorf, Henry Etzkowitz, José Mello, Marcelo Amaral, Alexander Uvarov, Poh Kam Wong). Destaca-se, ainda, a presença de quatro brasileiros, três norte-americanos, três cidadãos do Reino Unido e dois canadenses no grupo dos mais produtivos.

Se analisadas somente as comunicações em periódicos indexados, Loet Leydesdorff, Henry Etzkowitz respondem por cerca de 187 dos 643 artigos (29\%). Mesmo levando-se em 
conta que vários artigos foram escritos em conjunto e estão contabilizados duplamente, o volume é significativo.

No Quadro 5 são apresentadas as vinte instituições com maior número de entradas no banco de publicações. Destas, seis instituições são do Brasil, três dos Estados Unidos, duas do Reino Unido e duas da Rússia, sendo que todas são universidades, não havendo presença de institutos de pesquisa ou empresas. Nota-se que várias destas instituições são as de origem dos autores mais produtivos, e/ou foram organizadoras ou sedes de conferências. Quanto aos autores e suas instituições de filiação, pode-se citar: University of Amsterdam, na qual Loet Leydersdorff trabalhou durante toda a sua carreira; a State University of New York, Newcastle University e Stanford University (Henry Etzkowitz); a UFRJ (José Mello, Branca Terra, Mariza Almeida e Marcelo Amaral); a UFF (José Mello e Marcelo Amaral); a Laval University (Rejean Landry e Nabil Amara); Tomsk State University (Alexander Uvarov) e a University of Strathclyde (Girma Zawdie).

A presença de cinco instituições (Copenhagen Business School, Linköping University, National University of Singapore, Bandung Institute of Technology e Yeungnam University) está diretamente relacionada a organização/sede das conferências internacionais, a saber: 2002, 2007, 2012 e 2017, respectivamente. Isso significa que no ano em que a conferência foi organizada, diversos autores não ligados anteriormente ao movimento foram incentivados a participar. Pode-se intuir que se trata de pesquisadores em temáticas próximas ou relacionadas, e alunos de pós-graduação. A facilidade em termos de custo de deslocamento para a participação também tende a aumentar a presença de autores locais (da própria entidade ou vizinhas) ou do mesmo país.

As entidades University of Strathclyde e Tomsk State University estão em ambas as categorias, além de sediarem/organizarem conferências, também possuem autores bastante ativos (Girma Zawdie e Alexander Uvarov, respectivamente). Um detalhamento da quantidade de comunicações por ano em cada instituição pode trazer um painel mais claro sobre a participação de cada uma. 
Quadro 5 - Vinte instituições com maior número de comunicações

\begin{tabular}{|c|c|}
\hline Instituições ${ }^{1}$ & Quantidade e tipo de publicação \\
\hline University of Amsterdam (HOL) & 79 entradas ( 4 capítulos, 14 conferências, 60 periódicos, 1 relatório) \\
\hline State University of New York (EUA) & 58 entradas ( 3 livros, 3 capítulos, 6 conferências, 46 periódicos) \\
\hline UFF (BRA) & 31 entradas ( 25 conferências, 4 periódicos, 1 tese, 1 monografia) \\
\hline Bandung Institute of Technology (IND) & 28 entradas ( 28 conferências) \\
\hline Tomsk State University (RUS) & 26 entradas ( 24 conferências, 2 periódicos) \\
\hline USP (BRA) & 25 entradas ( 23 conferências, 2 periódicos) \\
\hline UFRJ (BRA) & 23 entradas ( 1 capítulo, 16 conferências, 6 periódicos) \\
\hline University of Strathclyde (ESC) & 22 entradas ( 1 capítulo, 14 conferências, 6 periódicos, 1 webinar) \\
\hline Copenhagen Business School (DIN) & 20 entradas (18 conferências, 2 periódicos) \\
\hline Yeungnam University (COR) & 20 entradas ( 6 conferências, 13 periódicos, 1 webinar) \\
\hline NC State (EUA) & 19 entradas ( 17 conferências, 2 periódicos) \\
\hline UFPR (BRA) & 18 entradas ( 8 conferências, 10 periódicos) \\
\hline Laval University (CAN) & 17 entradas (14 conferências, 3 periódicos) \\
\hline National University of Singapore (CIN) & 17 entradas (15 conferências, 2 periódicos) \\
\hline UNICAMP (BRA) & 17 entradas ( 15 conferências, 2 periódicos) \\
\hline Linköping University (SUE) & 16 entradas (12 conferências, 3 periódicos, 1 webinar) \\
\hline Stanford University (EUA) & 16 entradas ( 10 conferências, 5 periódicos, 1 working paper) \\
\hline Newcastle University (ING) & 15 entradas ( 2 capítulos de livros, 12 conferências, 1 periódico) \\
\hline PUC-RJ (BRA) & 15 entradas (12 conferências, 2 periódicos, 1 tese) \\
\hline Tomsk State University (RUS) & 15 entradas ( 15 conferências) \\
\hline
\end{tabular}

Fonte: Elaborado pelos autores.

${ }^{1}$ Os nomes originais em inglês foram mantidos, apenas as instituições brasileiras estão com as siglas pelas quais são conhecidas.

Em relação aos países de origem das comunicações, é possível verificar a forte presença do Brasil, Reino Unido, EUA, Holanda e Rússia, com mais de 100 comunicações cada um. Nestes casos, todos já sediaram ao menos uma conferência e contam com autores (e instituições) bastante ativos. Em um patamar abaixo, surgem países como Itália, Suécia, Canadá, Espanha e Indonésia. Exceto pelo Canadá, todos os demais também receberam uma edição da conferência. Nota-se, a partir da análise do Quadro 6, que 56,93\% das publicações estão concentradas apenas em 10 países dos 97 que integram o banco de comunicações. Isso permite inferir que existe uma ampla disseminação da abordagem da TH pelo mundo mas que a sua pesquisa está concentrada nas Américas e na Europa.

Sobre estes dados é importante comentar que os artigos em coautoria estão contabilizados somente uma vez, e que foram computados para o país do primeiro autor, 
considerado o principal. O país do autor é identificado pela instituição que ele informou no momento da publicação da comunicação.

Quadro 6 - Dez principais países

\begin{tabular}{|l|l|}
\hline \multicolumn{1}{|c|}{ Países } & \multicolumn{1}{c|}{ Quantidade e tipos de publicação } \\
\hline Brasil & $\begin{array}{l}\text { 423 entradas (1 livro, 7 capítulos de livros, 274 conferências, 3 working papers, } 7 \text { teses, } 19 \\
\text { dissertações, 1 relatório, 109 periódicos, 1 monografia, 1 não identificado) }\end{array}$ \\
\hline $\begin{array}{l}\text { Reino Unido } \\
\text { (UK) }\end{array}$ & $\begin{array}{l}246 \text { entradas (6 capítulos de livros, 182 conferências, 54 periódicos, 1 working paper, 1 } \\
\text { webinar, 2 relatórios) }\end{array}$ \\
\hline EUA & $\begin{array}{l}239 \text { entradas (4 livros, 4 capítulos de livros, 106 periódicos, 2 webinar, 3 working papers, } \\
119 \text { conferências, 1 não identificado) }\end{array}$ \\
\hline Holanda & 129 entradas (4 capítulos de livros, 45 conferências, 78 periódicos, 1 relatório, 1 webinar) \\
\hline Rússia & 112 entradas (98 conferências, 12 periódicos, 1 working paper, 1 não identificado) \\
\hline Itália & 96 entradas (68 conferências, 22 periódicos, 2 não identificados) \\
\hline Suécia & $\begin{array}{l}96 \text { entradas (1 livro, 63 conferências, 28 periódicos, 1 webinar, 1 working paper, 2 não } \\
\text { identificados) }\end{array}$ \\
\hline Canadá & 71 entradas (56 conferências, 15 periódicos) \\
\hline Espanha & 67 entradas (43 conferências, 24 periódicos) \\
\hline Indonésia & 58 entradas (58 conferências) \\
\hline
\end{tabular}

Fonte: Elaborado pelos autores.

Outra análise relevante que o banco de publicações permite, é em relação aos temas mais abordados. O Quadro 7 apresenta os principais temas discutidos nas conferências, sendo possível considerar os temas relações universidade-empresa-governo (UIG); geração, transparência e utilização do conhecimento; gestão de relações TH e redes, como os mais presentes. Para esta análise houve um esforço em agregar os temas similares. Os conteúdos foram coletados nos anais, nas programações e nas chamadas de artigos. Em algumas conferências há uma conexão direta entre as áreas temáticas da chamada (tracks) e suas sessões.

Em outros temas essa relação não foi encontrada. Arbitrariamente foi feito um corte de assuntos que tenham aparecido pelo menos em cinco conferências (1/3 do total), e identificouse treze que podem ser denominados como as discussões tradicionais ou consolidadas no campo. Estes são, em algum aspecto, os que compõem uma agenda de pesquisa do movimento. 
Quadro 7 - Principais temas discutidos

\begin{tabular}{|l|c|}
\hline \multicolumn{1}{|c|}{ Temas } & Quantidade \\
\hline Relações UIG & 16 \\
\hline Geração, transferência e utilização do conhecimento & 13 \\
\hline Gestão de relações TH e redes & 12 \\
\hline TH e construção/acumulação de capacidades & 9 \\
\hline Implementação de modelos TH em empreendedorismo & 9 \\
\hline Trocas/experiências entre universidade, empresas e tecnologia & 8 \\
\hline Modelos de universidade empreendedora & 8 \\
\hline Da torre de marfim para o mundo comercial & 5 \\
\hline Inovação tecnológica e o modelo da TH & 5 \\
\hline Um novo paradigma para a troca de conhecimento & 5 \\
\hline Motivos e impactos da criação de empresas spin-offs & 5 \\
\hline Sinergia entre os atores integrantes da TH & 5 \\
\hline O modelo da TH e suas extensões/evoluções & 5 \\
\hline
\end{tabular}

Fonte: Elaborado pelos autores.

\subsection{Análise dos Países que Sediaram Conferências}

Uma última análise realizada neste trabalho é sobre o impacto da organização das conferências da TH. A instituição que se candidata, em geral, tem o propósito de apoiar a disseminação nacional do tema e de se inserir na rede internacional de pesquisa. Dessa forma, analisando a quantidade de artigos publicados por cada país ao longo do tempo, é possível ter uma percepção se houve impacto positivo em sediar a conferência, seja no envolvimento de autores e instituições daquele país no momento, e/ou posteriormente. Existem limitações quanto essa visão, principalmente relacionadas ao tamanho da comunidade científica de cada país e ao grau de internacionalização da mesma.

A primeira conferência foi realizada em 1996 na cidade de Amsterdã, pela University of Amsterdam . Este país, apesar de ser a origem de um dos cocriadores da abordagem, nunca teve uma presença ampla no movimento, conforme mostra a Figura 2. Aqui nota-se a presença desta universidade e do professor Leydesdorff, que sozinho, e em colaboração com outros autores, tem mais comunicações que o país todo. Sobre este ponto é importante retomar o comentário de que as comunicações estão sendo atribuídas a países em função da instituição informada pelo autor, e que está sendo considerado somente o país do autor principal.

A segunda conferência foi realizada nos Estados Unidos em 1998, pelo Science Policy Institute, uma unidade da State University of New York (SUNY). Desde então, autores e instituições norte-americanas foram ativos no movimento, com destaque para a própria SUNY e a Universidade de Stanford, conforme é apresentado na Figura 3. Uma segunda conferência foi organizada em 2011 (nona conferência), em Palo Alto, no momento em que a Universidade 
de Stanford sediava o Triple Helix Research Group, liderado pelo professor Henry Etzkowitz. A organização ficou a cargo do Human and Science Technology Advanced Research Institute (H-Star), unidade desta universidade, e o resultado foi o reforço da participação dos autores do país nos anos seguintes. Entretanto, nas últimas quatro conferências, o número de autores norteamericanos caiu significativamente. Talvez, como explicação plausível para tal queda, é o fato de que os eventos foram realizados na Ásia e na Europa durante o mês de setembro, período que coincide com o início do ano letivo no hemisfério norte.

A terceira conferência da TH foi organizada pela Universidade Federal do Rio de Janeiro, por meio da Coordenação de Pós-Graduação e Pesquisa em Engenharia (COPPE), e ocorreu no Brasil em 2000, com um seminário regional preparatório em 1999. Esta realização envolveu diversos parceiros a apoiadores nacionais como a Universidade do Estado do Rio de Janeiro (UERJ) e a Confederação Nacional da Indústria (CNI), além de órgãos governamentais como Secretaria de Ciência e Tecnologia do Estado do Rio de Janeiro (SECT-RJ), Financiadora de Estudos e Projetos (FINEP) e Conselho Nacional de Desenvolvimento Científico e Econômico (CNPQ). Foi a primeira conferência a contar com um grande número de parceiros e a ter mais de 400 delegados.

Nota-se, na Figura 4, que desde então houve a disseminação do tema junto à pesquisadores e entidades brasileiras, e que a presença destes nas conferências foi marcante, sendo o segundo maior conjunto de autores nos anos de 2005, 2009, 2010, 2013 e 2014, atrás somente dos nativos do país organizador. Além da conferência internacional, instituições brasileiras sediaram eventos menores em 1999 (Rio de Janeiro), 2009 (Porto Alegre) e 2011 (Fortaleza), que levaram à constituição de um capítulo da THA em 2013, hospedado atualmente na Universidade do Estado do Rio de Janeiro (UERJ). Uma teoria que justifica tal movimento é a possibilidade de que diversos membros da associação discordaram da saída do professor José Mello da vice-presidência da THA, e sua aposentadoria. Outra justificativa seria a falta de recursos para pesquisas e viagens ao exterior decorrentes da crise econômica, e corte de fundos para ciência, tecnologia e inovação (C\&T\&I) no Brasil.

A quarta conferência foi realizada em 2002, fruto da organização conjunta de instituições da Dinamarca (Copenhagen Business School) e da Suécia (Lund University). Aqui optou-se em tratar os países escandinavos em conjunto por ser essa a proposta da conferência. Apesar da presença de autores destes países ser constante nas conferências, conforme a Figura 5, o volume vem caindo desde que o evento se tornou anual em 2010. Há uma presença de pesquisadores das Universidades de Lund e Linköping, ambas da Suécia, o que coloca o país 
entre os mais produtivos. Nota-se ainda que a região é uma das principais afiliações dos proponentes do modelo da Hélice Quádrupla, que inclui a sociedade (AMARAL et al., 2020).

A quinta conferência foi realizada em 2005 pela Universidade Politécnica de Turim, sediada na mesma cidade, na Itália. Os autores italianos têm forte presença no tema (a THA é sediada na Itália), e seu maior volume de comunicações se deu entre 2005 e 2013, conforme mostra a Figura 6. Desde então constatou-se uma queda acentuada da participação dos autores deste país, possivelmente em função do corte de investimentos em C\&T\&I feito pelos governos italianos, ou pela realização de conferências fora da Europa. No caso da conferência na Rússia (em 2014), predominava na Europa Ocidental um sentimento contrário ao Governo Putin, em função da anexação da Crimeia, e pelo apoio ao governo da Ucrânia, então em guerra.

A sexta conferência foi sediada na National University of Singapore no ano de 2007. Apesar de ser um dos países com alto nível de desenvolvimento econômico e tecnológico, contando com universidades de reconhecimento internacional, os autores não se mantiveram presentes no movimento da TH, conforme mostra a Figura 7. Talvez sua comunidade científica, que estude o tema, seja pequena. É o único caso de país que sediou a conferência e não teve a liderança no volume de comunicações (neste evento a liderança foi dos EUA).

A sétima conferência foi realizada em 2009 na Universidade de Strathclyde na cidade de Glasgow, Escócia. A presença de autores do Reino Unido sempre foi ampla, conforme mostra a Figura 8, e reforçada após as conferências de 2009, de 2013 e 2018 (THC 11 - realizada em Londres por um consórcio entre o University College of London e a Birkbeck College University of London; e THC 16 realizada 2018 em Manchester, também organizada por um consórcio de instituições). Nota-se também que entre 2005 e 2010, o professor Etzkowitz atuou neste país, na Universidade de Newcastle.

A oitava conferência foi realizada em 2010. Por decisão do então grupo dirigente do movimento, a partir deste ano os eventos passaram a ser realizados anualmente, como parte de um esforço para a consolidação da THA, recém-criada. O evento foi organizado pelo International Institute of Triple Helix (IITH), do Centro Universitário La Salle Madrid. Os autores espanhóis têm presença limitada no movimento, conforme mostra a Figura 9. E, apesar do crescimento ocorrido em 2010, não houve impacto significativo da realização da conferência na Espanha na participação de autores do país nas conferências seguintes. Uma possível explicação é o encerramento das atividades do IITH em 2011 e da crise econômica que assolou o país até 2013. Dentre as entidades participantes destaca-se a Universidade Politécnica de Valência. 
A décima conferência foi realizada na Indonésia, em Bandung, em 2012, e contou com o apoio do governo deste país. Esta teve um caráter mais regional do que internacional, e a expressiva quantidade de trabalhos locais colocou o país na lista dos dez mais produtivos, mas o impacto não se manteve à posteriori, conforme os dados apresentados na Figura 10. Essa conferência foi uma tentativa de disseminar a TH na Ásia, mas que pode ser considerada malsucedida, pois os pesquisadores deste país não se mantiveram no movimento.

Em 2014, a décima segunda conferência foi realizada na Rússia, na cidade de Tomsk, sendo organizada pela Tomsk State University, com apoio de duas outras universidades locais, além da mobilização dos atores nacionais. As instituições russas têm participação ativa no movimento desde 2010, e a realização da conferência foi a consolidação desse movimento, conforme os dados da Figura 11. Apesar de ter sido pequena, com pouca presença dos países europeus, pode-se considerá-la bem-sucedida em seus propósitos, pois permitiu a criação de um capítulo da THA no país.

Em 2015, a conferência continuou seu esforço de disseminação na Ásia, sendo organizada na China, em Pequim (Beijing). A crescente presença de pesquisadores chineses no movimento se torna evidente e se deve muito ao papel da pesquisadora Chunyan Zhou, que foi uma das gestoras do IITH na Espanha e criadora do International Triple Helix Institute (ITHI), sediado em Palo Alto, Califórnia. Sua atuação vem colaborando de forma continuada e prolífica com Henry Etzkowitz desde 2005. Contudo, o que a Figura 12 mostra é que o volume de produção segue pequena (em relação ao tamanho do sistema de C\&T\&I do país), muito em função das colaborações e coautorias com autores ocidentais.

Em 2016, foi realizada a décima quarta conferência, na cidade de Heidelberg na Alemanha, tendo como organizador local o German Cancer Research Center (DKFZ). Autores e instituições alemãs nunca tiveram uma presença significativa no movimento da THA (exceto no ano de 2009 na TH7), conforme a Figura 13, e isso se manteve após o evento, apesar de haver pouco tempo (menos de 2 anos) para se analisar o impacto em sediar uma conferência. Como resultado um capítulo foi organizado para ampliar a participação destes pesquisadores.

A mais recente conferência incluída no banco foi realizada na Coréia do Sul, país que tem uma presença parca no movimento. Como o evento foi realizado em setembro de 2017 ainda não foi possível fazer análise do impacto, sendo relevante fazer uma análise da participação prévia, na qual o país tem presença limitada. Ainda em 2017 houve um seminário regional no Quênia, que também não foi analisado. No ano de 2018 ocorreram eventos em Manchester e nos Emirados Árabes (Dubai) que também não foram lançados na base. 


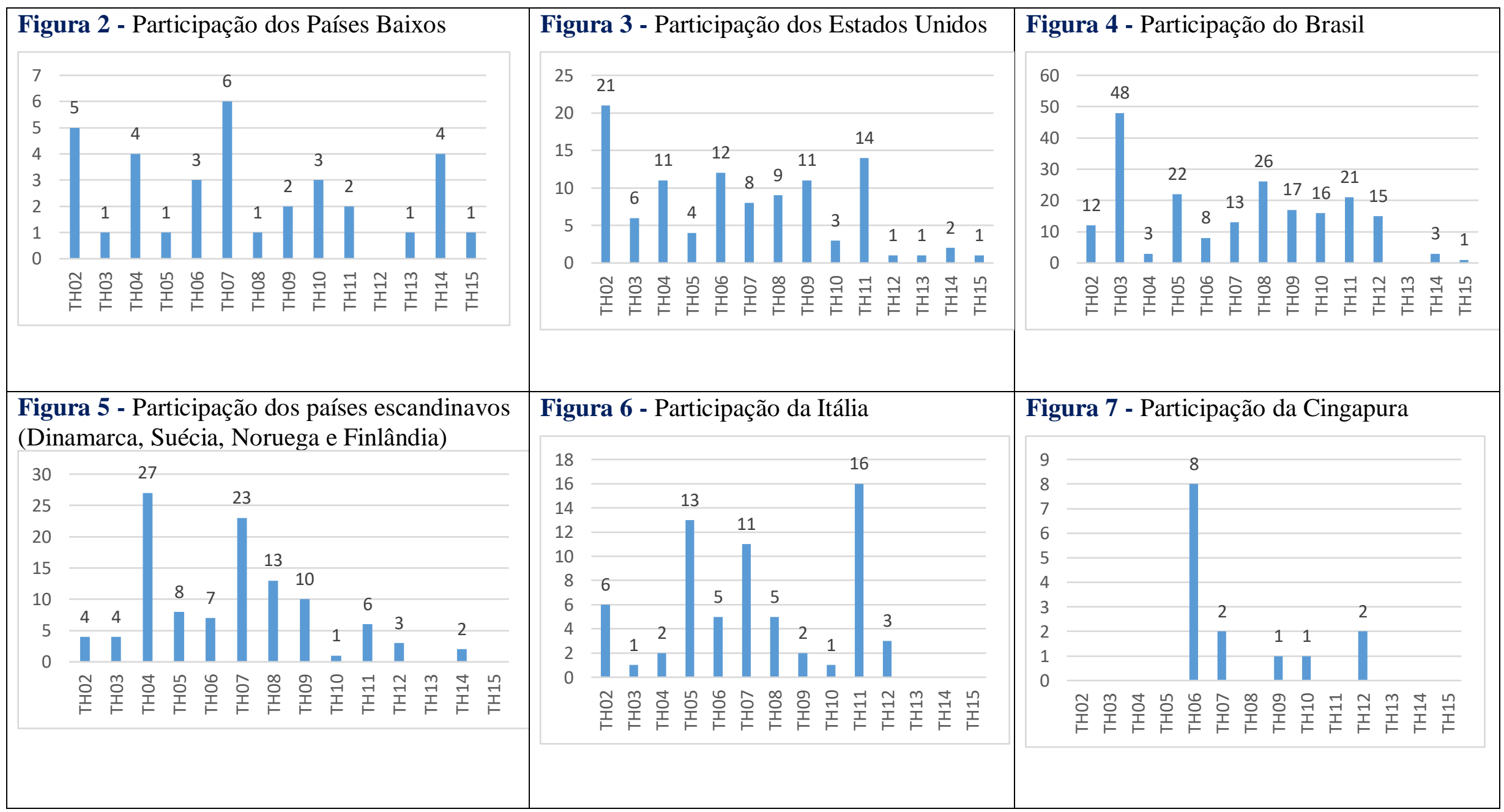




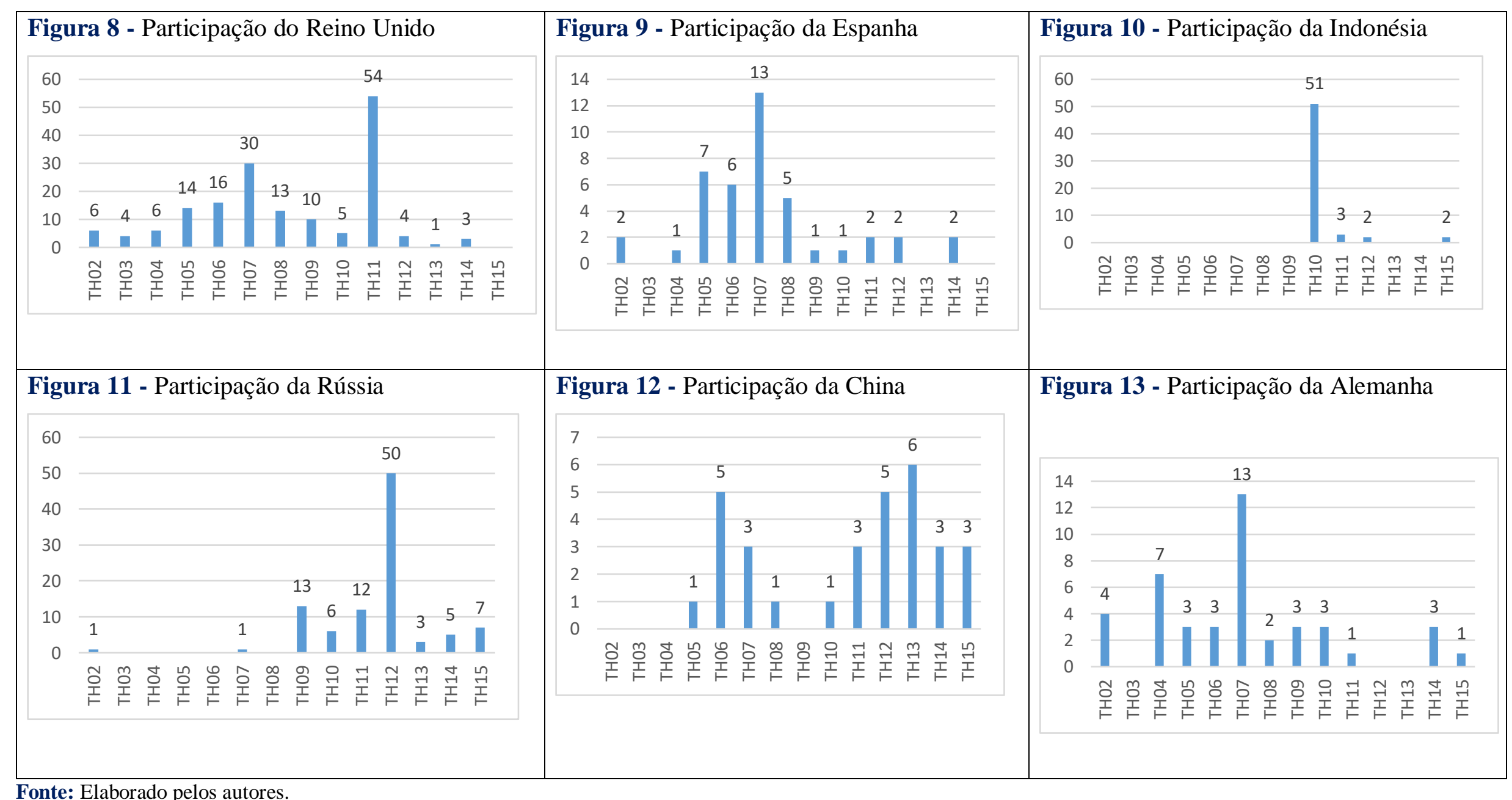




\subsection{Análise do Movimento da Triple Helix}

O objeto deste trabalho teórico-empírico foi de analisar a evolução do movimento da TH com base na análise do banco de comunicações científicas a partir da utilização de técnicas bibliométricas. A seção 2 descreveu brevemente as técnicas bibliométricas e o método utilizado. A seção 3 explicou a origem e estrutura do banco. As partes 4.1 e 4.2 apresentaram a análise das publicações permitindo ampliar o conhecimento e compreender a evolução do movimento acadêmico ao longo dos anos.

O que se pode perceber é que o tema se difundiu pelo mundo. Foram identificados 3.465 autores de 97 países que geraram 2.700 contribuições. Há um primeiro ciclo, entre 1996 e 2009, que pode ser considerado como de consolidação do movimento com as conferências bianuais. A partir de 2009, com o estabelecimento da THA, os eventos passam a ser anuais e cresce o volume de publicações em periódicos. Em um primeiro momento (até 2014) há aumento da produção total, mas o número de trabalhos publicados por evento diminui significativamente, o que continua nos eventos mais recentes. Nas primeiras conferências, mais de 100 trabalhos foram apresentados por edição enquanto nas últimas quatro conferências foram apresentados cerca de 50 trabalhos ou menos, em cada uma. De 2015 em diante há uma queda acentuada no volume de publicações total, mas não está claro se isso é uma tendência ou somente uma questão relacionada ao conteúdo da base de comunicações.

A intenção com a realização das conferências anuais certamente foi de expandir o movimento e fortalecer a THA, mas aparentemente o que está acontecendo é o inverso, e há sinais de que o movimento vem enfraquecendo. Note-se que o tema é um aspecto da discussão de gestão da inovação, que está inserida na subárea de estratégia na área da Administração. Pode-se compreender, ainda, o tema inovação, empreendedorismo e desenvolvimento como temas transversais ligados à economia, sociologia e áreas da engenharia. Desta forma, neste contexto, existem diversas associações e eventos concorrentes (UINN, IAMOT, ISPIM, IASP, EUROMOT, ALTEC, PICMET, IAOIP, AUTM, AURP), e boa parte delas possuem revistas acadêmicas próprias ou em parceria.

Não se encontrou um padrão ou modelo na forma de organização dos eventos, e a falta de um foco claro e de um padrão na organização das conferências certamente afeta a forma de difusão do tema. Talvez a realização de conferências a cada 2 ou 3 anos fosse mais eficiente. Assim como fazer eventos com parceiros mais sólidos e de expressão global, não apenas local/regional, e com uma gestão mais ativa da THA. Entidades como a ISPIM (International Society for Professional Innovation Management) realizam três eventos por ano com gestão 
própria, tendo focos e temas claros e a agenda disponibilizada com cerca de um ano de antecedência.

O próprio Triple Helix Journal publica um volume pequeno de trabalhos e para manter o acesso aberto (o que é importante para difundir o conteúdo), tem uma cobrança de taxa de publicação, o que cria barreiras para a participação de diversos autores. Entidades como a IAOIP (Internacional Association of Innovation Professional) mantêm periódicos de acesso livre, sem cobrança de taxas.

Outro ponto relevante é a falta de atividades específicas para os jovens alunos (em geral doutorandos). Em algumas conferências foram organizadas sessões específicas, e um prêmio foi criado pela THA em 2018, mas a falta de práticas como esta fazem com que não haja engajamento de novos autores. Comunidades como a Globelics, voltada para o desenvolvimento regional, tem uma academia na qual anualmente um conjunto de alunos de diversas partes do mundo se reúnem, por duas, semanas para discutir suas pesquisas e teses de doutoramento.

Comenta-se, ainda, que a realização das conferências em locais distantes da Europa e dos EUA faz com que a quantidade de pessoas presentes, e de artigos publicados, diminua consideravelmente, apesar de ser uma estratégia importante para disseminar globalmente o conceito. Uma possibilidade seria, em sendo a conferência principal a cada dois ou três anos, organizar seminários regionais nos intervalos.

Por fim, parece que o movimento da TH nasceu no eixo do Atlântico, porém, mais recentemente, se mostra como um movimento sino-russo. A adição de comunicações mais recentes mostrará se essa translação é pontual, por confluência de interesses dos atores locais com os gestores da THA, ou se será algo permanente. Há indícios a serem confirmados (pelo baixo número de publicações recentes) de um desgaste da temática nos países europeus e nos EUA, algo que pode estar ligado à emergência de modelos derivados com mais atores e hélices (Quadruple e Quíntuple Helix) (Amaral et al., 2020).

Sobre o impacto de sediar uma conferência, a realização do evento pode ampliar a presença de um país na rede, como ocorrido em inúmeros casos, mas não há garantia que isso possa ocorrer. É razoável supor que países com um sistema de inovação consolidado ou em evolução, como nos países que integram os BRICS, o interesse na discussão das relações entre atores das esferas universidade, empresa e governo seja maior, mas diversos fatores afetam tal envolvimento. De doze países analisados (nas Figuras 2 a 13), quatro não se mantiveram na rede (Cingapura, Indonésia e Alemanha, sendo o caso da Holanda atípico) enquanto oito países 
não só se mantiveram como lideram diversos indicadores (casos de Brasil, Estados Unidos, Rússia e Reino Unido, por exemplo).

\section{Considerações finais}

O objeto deste trabalho teórico-empírico foi analisar a evolução do movimento da TH com base na análise do banco de comunicações científicas por meio de técnicas bibliométricas. A seção 2 descreveu as técnicas, a seção 3 explicou os métodos e a origem e estrutura do banco, enquanto a parte 4 apresentou a análise das publicações, permitindo ampliar o conhecimento e compreender a evolução do movimento acadêmico ao longo dos anos.

A pergunta "Quem são os principais autores, instituições e países, e quais são suas agendas de pesquisa?" foi respondida nos quadros 4 a 7. Os propositores da TH (Henry Etzkowitz e Loet Leydesdorff) seguem sendo os autores mais ativos e que disseminaram mundialmente a abordagem a partir do engajamento de um grande número de pesquisadores e instituições acadêmicas de diferentes países. Após vinte e quatro anos de proposição, a TH mantém-se como um tema relevante, o que é referendado pelo volume de comunicações científicas realizadas.

$\mathrm{Na}$ análise dos temas significativos dentro da abordagem, e dos atores mais presentes, notou-se expressiva participação de instituições brasileiras, inglesas, norte-americanas, russas e italianas. Ficou evidenciada a falta de envolvimento de empresas e governos, configurando o movimento como eminentemente acadêmico, apesar do seu mote defender o relacionamento entre atores da tríade de esferas. Identificou-se, ainda, uma recente predominância de autores e entidades asiáticas (Russos e Chineses), indicando possíveis mudanças de orientação nas pesquisas.

Uma discussão secundária, sobre o impacto de sediar uma conferência, também foi realizada e mostrou que a maior parte dos organizadores e países envolvidos com a realização de uma conferência seguiram conectados ao movimento.

Este trabalho é uma contribuição real à Triple Helix Association, como entidade representante dos pesquisadores envolvidos com a temática, e para os gestores de futuros eventos. Além disso, é uma fonte de informação para pesquisadores que podem encontrar referências para revisão bibliográfica e lacunas/problemáticas para pesquisa/discussão acadêmica.

Entretanto, algumas limitações são evidentes e precisam ser tratadas futuramente. Por exemplo, o esforço para alimentar o banco de comunicações pode não conseguir abarcar toda a 
produção sobre o tema. Talvez por estar sediado no Brasil haja mais facilidade, em função da proximidade, de identificar produção científica de autores e instituições deste pais, criando um possível viés nos dados. Para minimizar essa limitação duas possibilidades estão sendo estudadas: discute-se a estruturação de um comitê de curadores com representantes de grupos de pesquisa espalhados por diversos países, o que poderia dar uma dimensão mais global ao projeto; ou, que este esforço seja encampado pela THA.

Uma segunda limitação do banco é a impossibilidade de se fazer análise das redes de coautoria no formato atual. Sendo, portanto, necessário a migração para alguma ferramenta de gestão de banco de dados ou de análise bibliométrica que contemple essa informação de forma estruturada.

Outra dificuldade está em se analisar o impacto das publicações. Atualmente calcula-se apenas o volume, devido à complexidade de manter o montante de citações, quase três mil publicações, atualizadas, visto que os indicadores quantitativos de citações mudam ao longo de tempo. Poder-se-ia utilizar o fator de impacto da respectiva revista, mas isso só atenderia uma parcela das publicações, pois não existe tal impacto para publicações em anais de congressos.

Por fim, comenta-se que a questão de acesso à fontes de recursos para tal tipo de atividade também se mostra limitada, o que dificulta o seu maior desenvolvimento. Uma possibilidade é se abrir o banco para que seja desenvolvido de forma colaborativa por distintos atores, como a Wikipedia.

Quanto à sugestões de pesquisas futuras, mantendo-se a atualização do conteúdo do banco, novas métricas poderiam ser introduzidas, como a montagem de uma rede de cocitação para os artigos indexados em bases como Web of Science, o que permitiria analisar separadamente o que está indexado e o que não está. Além do uso de indicadores como o Altmetrics para artigos ou o índice H do Google Scholar; e o score do Research Gate para pesquisadores, que podem trazer dados adicionais de temas e autores líderes e emergentes. É possível ainda se fazer análises por instituição ao longo do tempo, e a partir destes dados fazer estudos, por meio de entrevistas e survey com as entidades, compreendendo melhor o seu envolvimento com a temática e o movimento.

\section{Referências}

Alvarado, R. U. (2007). A bibliometria: história, legitimação e estrutura. In: Toutain, L. M. B. B. (org) Para entender a ciência da informação, 185-219, Salvador: EDUFBA. 
Amaral, M.; Faria, A. \& Schocair, M. (2020). Assessing The Innovation Environment Of The Research Triangle Region. Revista de Administração, Sociedade e Inovação, 5(2), p. 90 111. DOI: $10.20401 /$ rasi.6.2.386

Amaral, M. G. \& Ferreira, A. (2013). Triple Helix Movement Evolution: a Database from Academic Communications. Triple Helix International Conference 2013 - Book of Abstracts. London.

Amaral, M.; Ferreira, A. \& Teodoro, P. (2011). Building an entrepreneurial university in Brazil: The role and potential of university-industry linkages in promoting regional economic development. Industry and Higher Education, 25(5): 383-395.

Egghe, L. (1994). Bridging the gaps: conceptual discussions on informetrics. Scientometrics, 30(1): 35-47.

Etzkowitz, H. (2008). The Triple Helix: Industry, University, and Government in Innovation. Social Science Information, 42(3): 293-337.

Giusti, L. J. M.; Campos, L. M. S.; Peixe, B. C. S. \& Trierweiller, A. C. (2011). Sustentabilidade na engenharia de produção: um estudo bibliométrico de 2001 a 2011. Artigo apresentado no Simpósio de Engenharia de Produção, Bauru, Brasil.

Glänzel, W. \& Schoepflin, U. (1994). Little scientometrics, big scientometrics... and beyond?. Scientometrics, 30(2-3): 375-384.

Mueller, S. (2013). Estudos métricos da informação em ciência e tecnologia no Brasil realizados sobre a unidade de análise artigos de periódicos. Metrical studies on science and technology information in Brazil having the scientific article as unit of analysis. LIINC em Revista, 9(1): 6-27.

Otlet, P. (1934). Traité de documentation: le livre sur le livre, théorie et pratique. Editiones mundaneum.

Rosa, J. A. A.; Messias, N. R.; Amaral, M. G. (2018). The Triple Helix Movement: An Analysis of Academic Communications. Proceedings of XVI Triple Helix Conference, Manchester.

Santos, P. M. L. (2007). Paul Otlet: um pioneiro da organização das redes mundiais de tratamento e difusão da informação registrada. Ciência da Informação, 36(2): 54-63.

Sengupta, I. N. (1992). Bibliometrics, informetrics, scientometrics and librametrics: an overview. Libri, 42(2): 75-98.

Silva, M. R.; Hayashi, C. R. M. \& Hayashi, M. C. P. I. (2011). Análise bibliométrica e cientométrica: desafios para especialistas que atuam no campo. InCID: Revista de Ciência da Informação e Documentação, 2(1): 110-129.

Tague-Sutcliffe, J. (1992). An introduction to informetrics. Information processing \& management, 28(1): 1-3. 
Vanti, N. A. P. (2002). Da bibliometria à webometria: uma exploração conceitual dos mecanismos utilizados para medir o registro da informação e a difusão do conhecimento. Ciência da informação, 31(2): 152-162. 